\title{
Pure agraphia after deep left hemisphere haematoma
}

\author{
B Croisile, B Laurent, D Michel, M Trillet
}

\begin{abstract}
Pure agraphia is reported following haematoma in the left centrum semiovale sparing both parietal and frontal cortices. There was total inability to produce graphemes in the absence of limb apraxia. The lesion is assumed to have prevented linguistic and graphemic systems from gaining access to the frontal motor programme.
\end{abstract}

Pure agraphia is a written language disorder which occurs without oral language, reading ability or praxis being affected. There has always been controversy about the localisation of the lesion responsible. Initial evidence favoured the foot of the second left frontal gyrus $^{1-8}$ but several recent papers have demonstrated that pure agraphia can also occur following left parietal lesions. ${ }^{29-18}$

This report has two purposes. Firstly, it presents a new case of a rare disorder. Secondly, the anatomical localisation of the lesion is uncommon: it is a deep lesion which has not affected the frontal and parietal cortices. Thus a disconnection hypothesis is proposed: disruption between 1) the linguistic and praxic parietal centres and between 2) the motor and premotor frontal centres.

\section{Case report}

A 41 year old right handed doctor had been receiving anticoagulant therapy since 1981 for an aortic Bjork prosthesis. He had always written and performed skilled activities with his right hand. On February 18, 1988, he developed micrographia. A few hours later he was unable to either write or sign a letter, although he could dictate the contents to his secretary. His spontaneous speech, oral comprehension and reading aloud were normal. Both hands functioned normally with no motor deficit or clumsiness and that evening he was able to carry out repairs to the head-lights on his car. On 19 February, a frontal headache slowly developed and he was admitted to hospital. He exhibited a mild right central facial weakness and a slight weakness in the right arm. He had no sensory deficit. He was fully alert and oriented. Object naming was moderately impaired but there was no paraphasia. Oral and written comprehension, repetition and reading aloud were otherwise normal. He was unable to draw or write letters or words including spontaneous writing, dictation or copying. He could grasp the pen correc- tly but produced a meaningless scrawl for each letter or word (fig 1). He could draw geometric figures. Oral spelling and drawing of letters in the air with the upper-limb were disturbed at the onset but recovered a few days later. Writing with the left hand was not studied. The patient had no ideomotor apraxia and he could perform normally with objects. CT revealed a deep left hemisphere haematoma with intraventricular haemorrhage (fig 2). Angiography excluded a vascular malformation. A week later the motor deficit and word-naming impairment had disappeared but complete agraphia persisted for spontaneous writing, dictation and copying. The problem lay in actually writing or forming letters, as oral spelling was now completely correct. Reading was normal and he could recognise and pronounce correctly words spelled out to him. He had no finger agnosia, left-right disorientation or dyscalculia. On 8 March 1988, the agraphia had almost fully improved: writing was still slow and hesitant but without spelling errors.

\section{Discussion}

The interesting feature of this case is that predominantly the patient's writing had been impaired while his oral language and reading remained virtually unaffected. Pure agraphia is rare and clinical features and anatomical lesions are heterogeneous. There are two major subtypes: aphasic and apraxic. ${ }^{2319} 20$ In aphasic agraphia, letters are well-formed but spelling is inaccurate although it improves when copying; usually there is no difference between oral and written spelling. In apraxic agraphia, letters are poorly formed and do not improve with copying; oral spelling is normal. Pure agraphia is either isolated or is associated with symptoms which cannot explain the writing impairment. In our case the motor deficit and the mild anomic aphasia were not responsible for the agraphia. The patient's inability to produce letters in the air was related to a profound

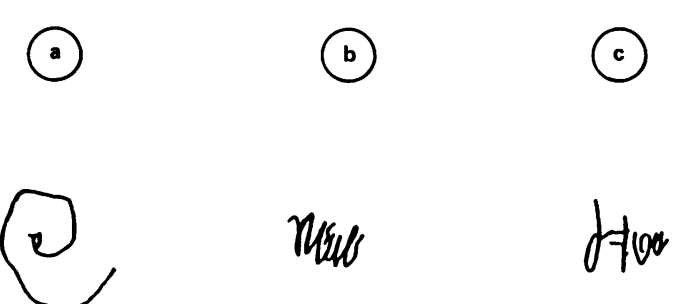

Figure 1 Initial writing under dictation-a) letter $P$, b) patient's name "Michel", c) "je suis à l'hôpital". 
Figure 2 a) and b) $C T$ scan: deep left hemispheric haematoma and intraventricular haemorrhage.
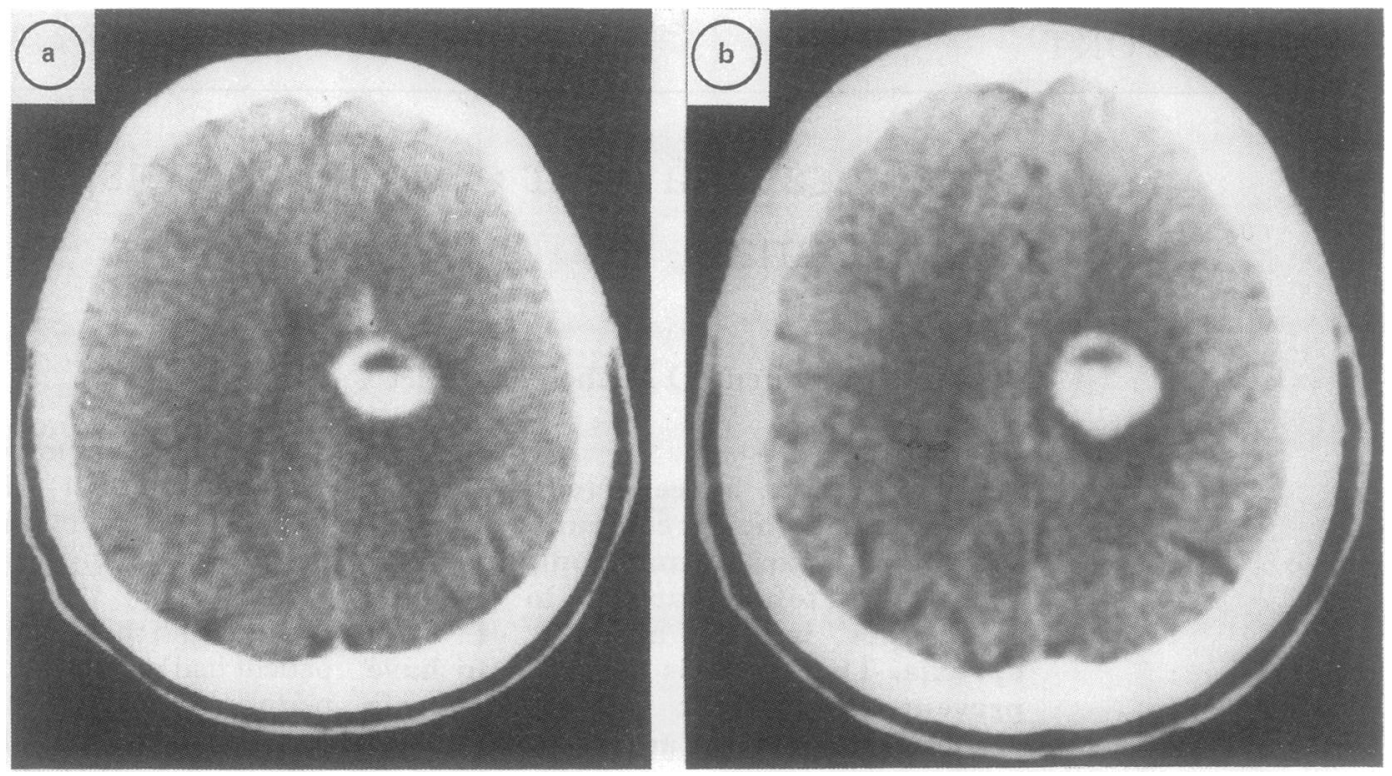

writing disturbance rather than to an impaired capacity to execute precise movements with the right hand.

In acute confusional states pure agraphia has been described with aphasic, apraxic and spatial features. ${ }^{21}$ However, in this case the patient did not exhibit an acute confusional state and it seems unlikely that an intraventricular haemorrhage could have been responsible for a nearly isolated writing loss.

The patient exhibited profound impairment of spontaneous, copied or dictated grapheme production. Visual and phonological word representations remained intact because reading, repetition, recognition of words spelled aloud and oral language were normal. There was no limb apraxia: the patient was able to perform gestures normally with both hands on command and there was no apraxia for object use. This absence of limb apraxia indicated that the patient's motor programming and visuokinesthetic engrams were intact. Engrams used for skilled motor movements are distinct from engrams used for guiding motor programming in grapheme production: they operate independently and in parallel. ${ }^{22}{ }^{23} \mathrm{~A}$ putative graphemic area is assumed to distinguish the features of the graphemes and to code selection, timing and spatial organisation of skilled motor movements used in writing. These engrams, located in the dominant parietal lobe, activate the motor programme in the frontal lobe which controls graphic output. The inability to write graphemes or to produce them in the air therefore suggests destruction of the graphemic area or a disconnection between this graphemic area and the frontal motor programme. These pure apractic agraphias are now well documented. ${ }^{33-26}$

Roeltgen and Heilman ${ }^{24}$ and Roeltgen ${ }^{28}$ postulated activation of the graphemic area by two parallel spelling systems: a phonological system $^{29}$ and a lexical system. ${ }^{30}$ As for the graphemic area, the localisation of linguistic processes is believed to be in the dominant parietal lobe. ${ }^{22}$ In our case the linguistic disturbances were slight and transient (anomia, difficulties in oral spelling). Unfortunately nonmotor writing (typing, anagram letters) was not tested in our patient, so it is not possible to say if the agraphia included a linguistic impairment.

Pure agraphia is associated with left hemispheric lesions: foot of $F 2,{ }^{1-8}$ parietal lobe ${ }^{29-18}$ temporal lobe ${ }^{31}$ or basal ganglia. ${ }^{32}$ Agraphia occurring without limb apraxia has been observed following parietal lesion. ${ }^{32-26}$ In our case the haematoma was situated in the left medial semioval centre but it could have involved the body of the caudate nucleus. In the semioval centre the lesion could have led to the disruption of corona radiata fibres, of commissural fibres before or after their emergence from corpus callosum, and of intrahemispheric association fibres between the parietal and the frontal cortices (superior longitudinal fasciculus). Our observation shows a dissociation of agraphia from limb apraxia: this suggests interruption during the transfer of writing, but not praxic, information between the intact parietal and frontal cortices. The deep subcortical lesion prevents linguistic and graphemic systems from gaining access to the frontal motor systems involved in writing. after callosal lesions: ${ }^{33}$ the nondominant hemisphere is disconnected from the linguistic and motor programmes necessary for writing with the left hand. Pure agraphia that results from intrahemispheric disconnection is more unusual. But such a mechanism can be discussed in some observations with deep or medial lesions in the parietal lobe sparing cortical areas. $^{391118}$ It seems that praxis and maybe the linguistic processes used in writing can be impaired after nonparietal damage. For example, phonological agraphia has been observed not only following supramarginalis gyrus lesions but also following deep insula lesions, ${ }^{27}$ and lexical agraphia has been observed following focal lesion of the precentral gyrus. ${ }^{34}$ In our case, reading and repetition were intact and there was no limb apraxia but, in contrast, writing was defective: this means that there is a very selective disruption in the pathways linking the temporo-parietal
Left unilateral agraphia frequently occurs 
and frontal cortices, involving only fibres used for writing.

1 Exner S. Untersuchungen über die Lokalisation der Funktionen in der Grosshirnrinde des Menschen. Wein: Wilhelm Braumuller, 1881

2 Dubois J, Hecaen H, Marcie P. L'agraphie pure. Neuropsychologia 1969;7:271-86.

3 Baxter DM, Warrington EK. Ideational agraphia: a single case study

4 Gordinier HC A case of brain tumor at the base of the second left frontal circonvolution. Am J Med Sci 1899; 117:526-35.

5 Mahoudeau D. Considérations sur l'agraphie, à propos d'un cas observé chez un traumatisé du crâne porteur d'une lésion des 2ème et 3ème circonvolutions frontales gauches. Sem Hop Paris 1950;1598-601.

6 Mahoudeau D, David M, Lecoeur J. Un nouveau cas d'agraphie sans aphasie, révélatrice d'une tumeur métastatique du pied de la 2ème circonvolution frontale gauche. Rev Neurol (Paris) 1951:159-61.

7 Penfield W, Roberts L. Speech and brain mechanisms. Princeton: Princeton University Press, 1959.

8 Aimard $G$, Devic $M$, Lebel $M$, Trouillas $P$, Boisson $D$. Agraphie pure (dynamique?) d'origine frontale. $R e v$ Neurol (Paris) 1975;7:505-12.

9 Russel LW, Espir MLE. Traumatic aphasia. Oxford University Press, 1961 .

10 Kinsbourne M, Rosenfield D. Agraphia selective for written spelling, an experimental case study. Brain Lang 1974, $1: 215-25$.

11 Bruyer R, Collignon R, Rectem D, Laterre EC. Agraphie transitoire pure ou d'evocation par lésion tumorale pariéto-occipitale gauche chez une droitière. Acta Neurol Belg 1977;77:321-30.

12 Basso A, Taborelli A, Vignolo LA. Dissociated disorders of speaking and writing in aphasia. J Neurol Neurosurg Psychiatry 1978;41:556-63.

13 Bruyer R, Rectem D, Collignon R, Laterre EC. Agraphie pure bilatérale, astéréognosie droite et troubles du calcul par lésion tumorale parietale gauche. Acta Neurol Belg 1978;78:193-206.

14 Mazzocchi E, Vignolo LA. Localization of lesions in aphasia: clinical CT scan correlations in stroke patients. Cortex 1979;15:627-54.

15 Auerbach SH, Alexander MP. Pure agraphia and unilateral optic ataxia associated with a left superior parietal lobule lesion. Neurol Neurosurg Psychiatry 1981;44:430-2.

16 Paolino E, De Bastiani P. Monetti VC, Boldrini P, Rosati G. Pure "aphasic" agraphia due to damage of the left superio parietal lobule. Ital J Neurol Sci 1983;2:233-7.

17 Miceli G, Silveri C, Caramazza A. Cognitive analysis of case of pure dysgraphia. Brain Lang 1985;25:187-212.

18 Trillet $M$, Croisile B, Laurent B. L'agraphie pure. A propos de deux cas. Rev Neurol (Paris) 1989;145:720-4.

19 Ogle JW. Aphasia and agraphia. In: Report of the Medical Research Council of St George's Hospital (London), 1867. Vol 2:28-122.

20 Strub RL, Geschwind N. Localization in Gerstmann syndrome. In: Kertesz A, eds. Localization in Neuropsychology. New York: Academic Press, 1983.

21 Chedru E, Geschwind N. Writing disturbances in acute confusional states. Neuropsychologia 1972;Vol. 10:343-53.

22 Rothi L, Heilman KM. Alexia and agraphia with spared spelling and letter recognition abilities. Brain Lang
s.

23 Coslett HB, Rothi L, Valenstein E, Heilman KM. Dissociations of writing and praxis: two cases in point. Brain Lang 1986;28:357-69.

24 Roeltgen DP, Heilman KM. Apractic agraphia in a patien with normal praxis. Brain Lang 1983;18:35-46.

25 Margolin DI. The neuropsychology of writing and spelling: semantic, phonologic, motor, and perceptual processes. O J Exp Psychol 1984;36A:459-89.

26 Crary MA, Heilman KM. Letter imagery deficits in a case of pure apraxic agraphia. Brain Lang 1988;34:147-56.

27 Roeltgen DP, Heilman KM. Lexical agraphia: further support for the two-system hypothesis of linguistic support for the two-system hypo

28 Roeltgen DP. Agraphia. In: Heilman KM, Valenstein E, eds. Clinical Neuropsychology, 2nd ed. New York: Oxford eds. Clinical Neuropsychol

29 Shallice T. Phonological agraphia and the lexical route in writing. Brain 1981;104:412-29.

30 Beauvois MF, Derouesne J. Lexical or orthographic agraphia. Brain 1981;104:21-49.

31 Rosati G, De Bastiani P. Pure agraphia: a discrete form of aphasia. J Neurol Neurosurg Psychiatry 1979;42:266-9.

32 Laine T, Marttila R. Pure agraphia: a case study. Neuropsychologia $1981 ;$ Vol. 19;2:311-6.

33 Liepman H, Maas O. Fall von linksseitiger: Agraphie und Apraxies bei rechtsseitiger Lähmung. J Psychol Neurol 1907;10:214-27.

34 Rapcsak SZ, Arthur SA, Rubens AB. Lexical agraphia from focal lesion of the left precentral gyrus. Neurology 1988;38:1119-23. 